\title{
Determination of three-dimensional solution structure of waglerin I, a toxin from Trimeresurus wagleri, using 2D-NMR and molecular dynamics simulation
}

\author{
Li-Chin Chuang ${ }^{a}$, Hui-Ming Yu ${ }^{a}$, Chinpan Chen ${ }^{b}$, Tai-Huang Huang ${ }^{\text {b, }}$ \\ Shih-Hsiung Wu ${ }^{\text {a,c, * }}$, Kung-Tsung Wang a,c \\ a Institute of Biological Chemistry, Academia Sinica, P.O. Box 23-106, Taipei, Taiwan \\ ${ }^{\mathrm{b}}$ Institute of Biomedical Sciences, Academia Sinica, Taipei, Taiwan \\ ${ }^{\mathrm{c}}$ Institute of Biochemical Sciences, National Taiwan University, Taipei 106, Taiwan
}

Received 26 April 1995; revised 3 August 1995; accepted 16 August 1995

\begin{abstract}
The solution conformation of a synthetic snake venom toxin waglerin I, has been determined by using proton nuclear magnetic resonance spectroscopy. By a combination of various two-dimensional NMR techniques, the ${ }^{1} \mathrm{H}-\mathrm{NMR}$ spectrum of waglerin I was completely assigned. A set of 247 interproton distance restraints was derived from nuclear Overhauser enhancement (NOE) measurements. These NOE constraints, in addition to the 2 dihedral angle restraints (from coupling constant measurements) and $7 \omega$ torsion angle restraints for prolines, formed the basis of three-dimensional structure determined by molecular dynamics techniques. The 19 structures that were obtained satisfy the experimental restraints, and display small deviation from idealized covalent geometry. Analysis of converged structures indicates that the toxin has no special secondary structure. In the solution structure of waglerin I, the central ring region is well defined but the $\mathrm{N}$ - and $\mathrm{C}$-termini possesses more disorder.
\end{abstract}

Keywords: Waglerin; Nuclear magnetic resonance; Protein solution structure; Snake venom; Molecular dynamics simulation; (T. wagleri)

\section{Introduction}

Wagler's pit viper (Trimeresurus wagleri) is a small arboreal and toxic snake distributed from Malaysia, the Philippines, Thailand and the Indo-Australian archipelago to Indonesia, with a lirnited range on the mainland [1]. Smith and Hindle [2] suggested the presence of neurotoxins in $T$. wagleri venom according to the symptoms shown by mice. Minton [3] found a major toxic component of $T$.

\footnotetext{
Abbreviations: NMR, nuclear magnetic resonance; CD spectrum, circular dichroism spectrum; HPLC, high-performance liquid chromatography; DQF-COSY, double-quantum filtered correlation spectroscopy; TOCSY, total correlation spectroscopy; NOESY, nuclear Overhauser and exchange spectroscopy; NOE, nuclear Overhauser effect; TPPI, time-proportional phase incrementation; RMD, restrained molecular dynamics RMSD, root mean square deviation; TFA, trifluoroacetic acid; DMF, dimethylformamide; DMSO, dimethylsulfoxide; HMP resin, $p$-hydroxymethylphenoxymethylpolystyrene resin; EDT, 1,2-ethanedithiol; Fmocamino acid, $N$-fluorenylmethoxycarbonyl amino acid.

* Corresponding author. Fax: +88623635038.
}

wagleri which is stable to heating at $125^{\circ} \mathrm{C}$ for $15 \mathrm{~min}$ and can be removed by dialysis. The enzymatic activities, lethal toxins and a potent platelet aggregation inducer in the crude venom of Trimeresurus wagleri have also been studied [4,5]. Recently, two lethal peptides have been isolated from the venom of the snake by high-performance liquid chromatography. The primary sequences of the two main lethal peptides (called waglerins) have been determined to be as follows $[6,7]$ :

$$
5 \quad 10 \quad 15 \quad 20
$$

Waglerin I G G K P D L R P C H P P C H Y I P R P K P R Waglerin II G G K P D L R P C Y P P C H Y I P R P K P R

These two toxins (waglerin I and II) contain seven proline residues out of 22 amino-acid residues and a disulfide bond, and show highly basic and thermostable properties. Both waglerins have the same sequence except for residue 10 , where Tyr is present in waglerin II instead of His in waglerin $I$. Waglerin $I$ has a murine i.p. $L_{50}$ of 0.33 
$\mu \mathrm{g} / \mathrm{g}$ while waglerin II has a murine i.p. $\mathrm{LD}_{50}$ of 0.51 $\mu \mathrm{g} / \mathrm{g}$. The analogs (SL-I and SL-II) of waglerin I and II with an additional Ser-Leu on the amino terminus have also been isolated from the venom of the snake. SL-I is slightly more toxic than waglerin I [7].

From previous studies of their structure-function relationships, the intramolecular disulfide bond in these lethal peptides is essential for their biological activity [7]. Waglerin I can be inactivated by chymotrypsin cleavage at Tyr-15. The two peptide products, residues $1-15$ and 16-22, alone or in combination, had no effect on mice [7]. Waglerin I retained full toxicity after autoclaving at $121^{\circ} \mathrm{C}$ for $40 \mathrm{~min}$. This reveals that waglerins are extremely stable at high temperature [7].

The mechanism of action of waglerins has not yet been fully elucidated. In preliminary studies, the toxin appear to resembles vasoactive peptide or neurotoxins. However, the toxin lacks antigenic identity with a number of representative neurotoxins and myotoxins. More recently, several reports have described multiple functions of the toxin [8-11]. Respiratory failure is the primary cause of death from the toxin in mice but rats are rather resistant to waglerin I [9]. The toxin $(10 \mu \mathrm{g} / \mathrm{ml})$ does not alter the amplitude of sodium and potassium currents of the nerve terminal, but it causes decreased in the calcium current. The toxin acts at both pre- and post-synapse neuromuscular junctions of the mouse motor endplate and that its presynaptic effect is apparently more potent than the postsynaptic effect. Thus, any hypotensive effect could be secondary to peripheral neurotoxicity.

We have synthesized waglerin I by the method of automatic solid-phase peptide synthesis and air oxidation. After purification by HPLC, the synthetic waglerin I was characterized by amino-acid analysis, ion-electrospray mass spectroscopy, and bioassay in comparison with native waglerin I. In order to obtain the tertiary structure of waglerin I, the toxin was studied by a combination of NMR and molecular modeling techniques. The results allow us to speculate on the relationship between structure and function.

\section{Material and methods}

\subsection{Chemical synthesis of waglerin I}

Waglerin I was synthesized by solid-phase peptide synthesis using an ABI automated peptide synthesizer. Starting with $0.25 \mathrm{mmol}(0.295 \mathrm{~g})$ of HMP resin $(0.85 \mathrm{mmol} / \mathrm{g})$, synthesis was carried out in a stepwise Fast Moc $^{\mathrm{TM}}$ protocol. The amino acids were introduced using the manufacturer's prepacked cartridges ( $1 \mathrm{mmol}$ each). Side-chain protection was arginine(Pmc), asparagine(Trt), aspartic $\operatorname{acid}(\mathrm{OtBu})$, cysteine(Trt), glutamic acid(OtBu), histidine(Trt), lysine(Boc), tyrosine(tBu); Pmc, 2,2,5,7,8pentamethylchroman-6-sulfonyl; Trt, trityl; OtBu, tert- butyl ester; Boc, tert-butyloxycarbonyl; tBu, tert-butyl. Double coupling was used for arginine $(\mathrm{Pmc})$ and proline. After synthesis, $0.54 \mathrm{~g}$ peptide resin was placed in a round-bottom flask that contained a micro stir bar. The cool mixture containing $0.75 \mathrm{~g}$ crystalline phenol, $0.25 \mathrm{ml}$ EDT, $0.5 \mathrm{ml}$ thioanisole, $0.5 \mathrm{ml}$ deionized $\mathrm{H}_{2} \mathrm{O}$ and $10 \mathrm{ml}$ TFA was put into the flask. After stirring at room temperature for $2-3 \mathrm{~h}$, the reaction mixture was concentrated on a rotary evaporator and the temperature of the water bath was maintained below $40^{\circ} \mathrm{C}$ to prevent damage to the peptide that might have been caused by heat. Dichloromethane $(10-20 \mathrm{ml})$ was added to help the solution evaporate. The residue was further lyophilized. Then, the residue was triturated with cold ether, filtered, and washed with about $200 \mathrm{ml}$ cold ether. The filtered residue was immediately transferred to 1.7 liters of a stirred solution of dilute acetic acid $\left(0.4 \% \mathrm{AcOH}\right.$ in $\left.\mathrm{H}_{2} \mathrm{O}\right)$. After stirring for several minutes, the $\mathrm{pH}$ of the solution was adjusted to $\mathrm{pH} 8.0$ with ammonium hydroxide. After filtration to remove resin, the solution was maintained without stirring at room temperature for $4 \mathrm{~h}$. Analytical HPLC was used to monitor the progress of the oxidation. The oxidized solution was then lyophilized. The product was dissolved with $0.4 \%$ acetic acid solution and filtered to remove the insoluble material. The filtrate was purified by HPLC using a $\mathrm{C}_{18}$ column $(10 \mu \mathrm{m}$ particle size, $250 \times 4.6 \mathrm{~mm})$ with a gradient $(0-100-100 \%$ solvent $B$ in $0-40-45 \mathrm{~min})$ of solvent $\mathrm{A}$, acetonitrile $/ \mathrm{H}_{2} \mathrm{O} /$ trifluoroacetic acid $=$ $5 / 95 / 0.1$ and solvent $\mathrm{B}$, acetonitrile $/ \mathrm{H}_{2} \mathrm{O} /$ trifluoroacetic acid $=90 / 10 / 0.1$ at a flow rate of $1 \mathrm{ml} / \mathrm{min}$ with monitoring by absorbance at $214 \mathrm{~nm}$. The elution times were $13.2 \mathrm{~min}$ for reduced waglerin $\mathrm{I}$, and $12.8 \mathrm{~min}$ for oxidized waglerin I.

The synthetic peptide was characterized by ion-spray mass spectroscopy and amino-acid analysis. Mass spectra were determined by a VG Bio-Q Mass Spectrometer with an electrospray ion source. The amino-acid composition of the synthetic peptide was analyzed on a Beckman 6300 High Performance Analyzer.

\subsection{Circular dichroism}

CD spectra were performed with a Jasco J-720 spectropolarimeter. Spectra were measured between $300 \mathrm{~nm}$ and $185 \mathrm{~nm}$ in water jacketed, $0.2 \mathrm{~mm}$ quartz cell, using a 1.5 $\mathrm{nm}$ band width, $0.5 \mathrm{~nm}$ step and a $4.0 \mathrm{~s}$ time constant. For each spectrum, eight scans were averaged, corrected for solvent contributions and fitted using non-linear regression analysis.

\subsection{NMR measurements of waglerin I}

NMR spectra were obtained with a sample containing $20 \mathrm{mM}$ peptide in $90 \% \mathrm{H}_{2} \mathrm{O} / 10 \%{ }^{2} \mathrm{H}_{2} \mathrm{O}$. For determining the amide proton exchange rates, lyophilized peptide was dissolved in 99.996 atom $\%{ }^{2} \mathrm{H}$ and the NMR spectra were 
recorded at various times immediately after the dissolution. Samples were adjusted to a $\mathrm{pH}$ of 3.0 at $25^{\circ} \mathrm{C}$.

NMR spectra were recorded at $298 \mathrm{~K}$, using a Bruker AMX 600 spectrometer equipped with X32 computer. The data were processed on an INDIGO workstation using UXNMR software (Bruker). A set of standard two-dimensional spectra, including DQF-COSY [12], NOESY [13,14] and TOCSY $[15,16]$ experiment, were accumulated in the phase-sensitive mode [17,18] using time-proportional phase incrementation (TPPI). The mixing times $\left(\tau_{m}\right)$ of the NOESY experiments were 300 and $400 \mathrm{~ms}$. The NOESY data set consisted of 2048 data points in the $t_{2}$ dimension and 700 (TPPI method) $t_{1}$ increments. The TOCSY experiment was achieved by MLEV-17 spin-lock pulse sequence [16]. For DQF-COSY and TOCSY experiments, 2048 data points were acquired in the $t_{2}$ dimension with 1024 and $512 t_{1}$ increments, respectively. FIDs were multiplied by skewed phase-shifted sine bell window functions prior to complex Fourier transformation. Data were zero filled to 2048 data points in both dimensions. Vicinal ${ }^{3} J_{\mathrm{C} \alpha \mathrm{H}-\mathrm{NH}}$ coupling constants were measured from DQFCOSY spectrum. Cross peak taken along the $\omega_{2}$-axis were subjected to an inverse Fourier transformation zero-filled to 8092 data points and Fourier transformed to give a digital resolution of $0.8 \mathrm{~Hz}$ /point. Fourier transformation was carried out on an INDIGO workstation using Felix software (version 2.3.0). Amide hydrogens which are slow to exchange with solvent were identified by dissolving the sample in ${ }^{2} \mathrm{H}_{2} \mathrm{O}$ and immediately recording its $1 \mathrm{D}-{ }^{1} \mathrm{H}$ spectra.

\section{4. ${ }^{I} \mathrm{H}-{ }^{1} \mathrm{H}$ distance constraints derived from NOESY spec- tra}

The conformational constraints obtained from NMR measurements include two different types: (1) NOE distance constraints; (2) Torsional angles, $\phi$, constraints derived from spin-spin couplings ${ }^{3} J_{\mathrm{C} \alpha \mathrm{H}-\mathrm{NH}}$. A set of 247 structurally useful NOEs were first identified in $400 \mathrm{~ms}$ NOESY spectra in $\mathrm{H}_{2} \mathrm{O}$ and $500 \mathrm{~ms}$ NOESY spectra in ${ }^{2} \mathrm{H}_{2} \mathrm{O}$. These were then classified into three distance ranges, $1.8-2.8,1.8-3.3$ and $2.5-5.0 \AA$, corresponding to strong, medium and weak NOEs, respectively. The upper limits of distances involving methyl and methylene protons were corrected for center $\left\langle r_{\mathrm{c}}\right\rangle$ averaging [19]. For all NOEs involving methyl groups, an additional $0.5 \AA$ was

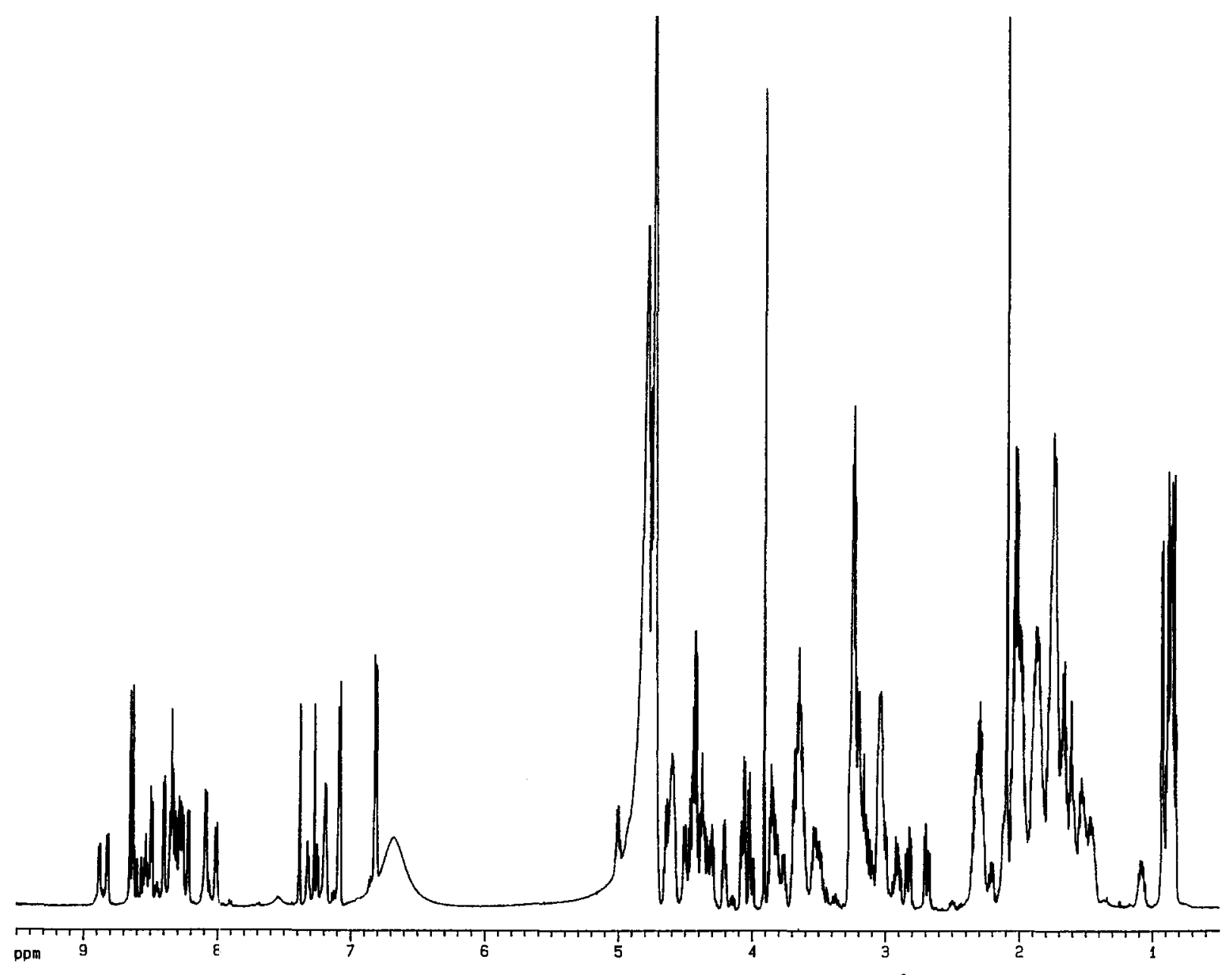

Fig. 1. One-dimensional proton spetrum of waglerin I dissolved in $90 \% \mathrm{H}_{2} \mathrm{O} / 10 \%{ }^{2} \mathrm{H}_{2} \mathrm{O}$ at pH 3.0. 
added to the upper distance limit. In addition to the NOE distance restraints, ${ }^{3} J_{\mathrm{C} \alpha \mathrm{H}-\mathrm{NH}}$ coupling constants were obtained in the fingerprint region of the DQF-COSY spectrum using the peak-to-peak separation of the antiphase fine structure components in the contour plots. For ${ }^{3} J_{\mathrm{C} \alpha \mathrm{H}-\mathrm{NH}}$ larger than $8.0 \mathrm{~Hz}, \phi$ is restricted to the range $\left[-80^{\circ},-160^{\circ}\right]$. Thus, backbone dihedral angle restraints were obtained for 2 residues only by using the Karplus relationship [20,21]. Finally, for cis-proline Pro-12 the $\omega$ torsion angle was constrained to $0 \pm 5^{\circ}$ and for the remaining trans-prolines to $180 \pm 5^{\circ}$.

\subsection{Tertiary structure computations}

All calculations were performed using the molecular mechanics package DISCOVER (Biosym Technologies) with CVFF [22] force field. Structures were created graphically using INSIGHT II (Biosym Technologies), which provides a particularly convenient interface to DISCOVER.

For calculations of molecular dynamics trajectories, the empirical energy function was used, which includes harmonic potential energy terms for bond lengths, bond angles, dihedral angles, functions for van der Waals and electrostatic interactions.

Solvent molecules were not explicitly introduced in the computations; instead their presence was simulated by the inclusion of a distance-dependent dielectric constant $[23,24]$. Furthermore, we added a distance-restraint function to the energy terms to include the NOE distance information.

The initial structure for the RMD calculation was generated by the computer model incorporating the extended chain conformation. All amide bonds were fixed to be trans except the peptide bond of Pro ${ }^{11}-$ Pro $^{12}$, which was

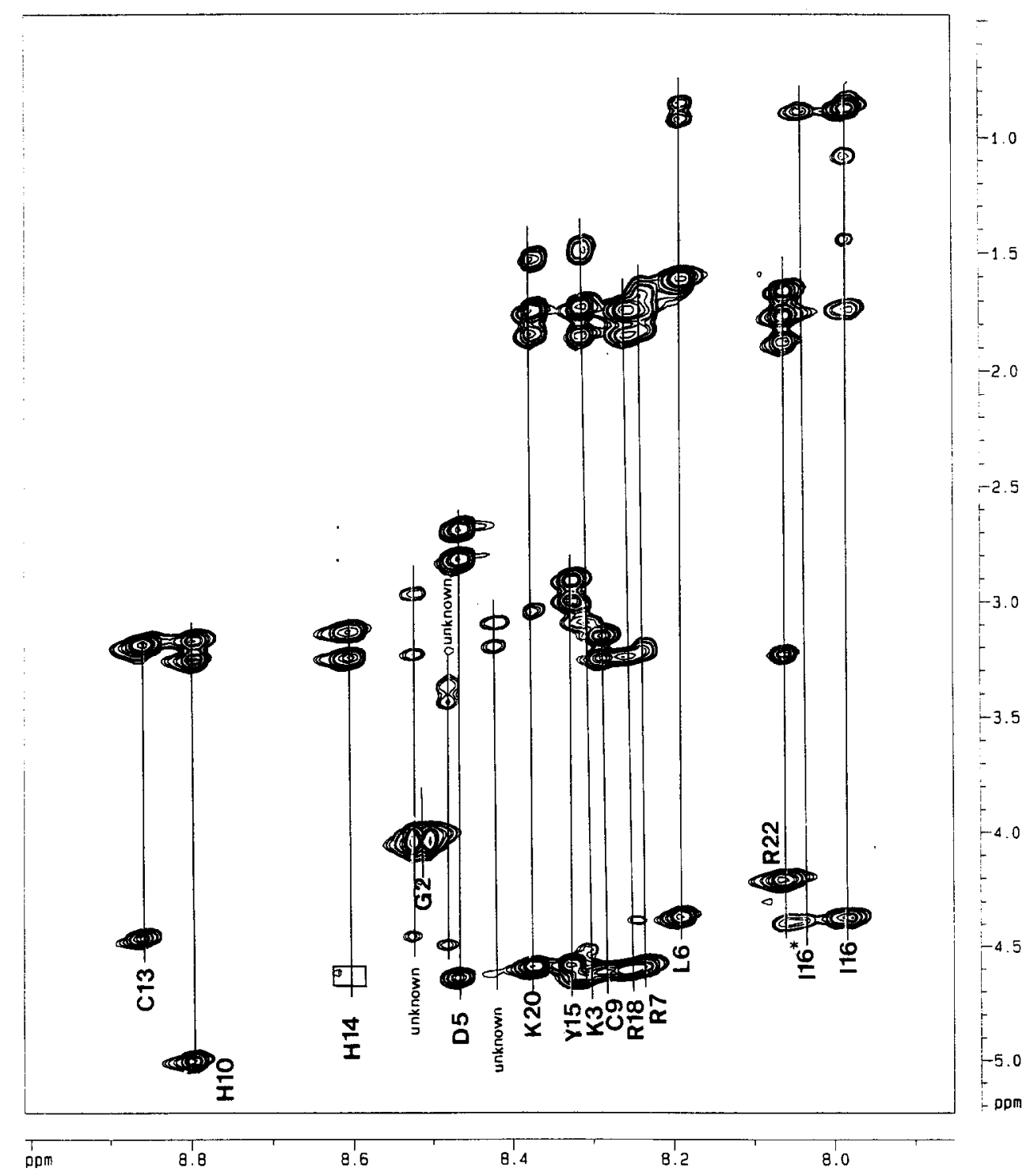

Fig. 2. NH-aliphatic region of the TOCSY spectrum of waglerin I dissolved in $90 \% \mathrm{H}_{2} \mathrm{O} / 10 \%{ }^{2} \mathrm{H}_{2} \mathrm{O}$ at pH 3.0. Relayed connectivities are indicated by continuous line. 
assumed to be cis due to the evidence of NOE pattern. The disulfide patching was applied to close the structure to a ring form. Using the interproton distance constraints for RMD simulation, we took explicitly into consideration all hydrogen or pseudo atoms to which the NOE constraints are referred. In total 247 distance constraints were applied.

The molecule was allowed to relax first by unconstrained energy minimization for 1000 steps of the Newton-Raphson method, to remove strains caused on definition of the interchain bonds. The molecule was first heated gradually from 0 to $600 \mathrm{~K}$ with velocities reassigned every 1 fs. Following this initial heating procedure, the molecule was then equilibrated for $4 \mathrm{ps}$ at $600 \mathrm{~K}$. The cooling process takes 4 ps with 1 fs time step. Finally a 20 ps molecular dynamic was carried out to relax the molecule.

\section{Results and discussion}

\subsection{NMR and molecular modeling}

Sequential assignments were achieved via the established procedure of first classifying the residues by type, secondly establishing connectivities between neighboring residues by proton-proton NOEs, and then identifying short segments of residues and matching these segments to the protein sequence [25]. Because of significant overlap in the $\mathrm{C}_{\alpha} \mathrm{H}$ and amide proton regions (Fig. 1), it was necessary to classify as many amino-acid spin systems as possible before beginning the sequential assignments.

\subsection{Amino-acid spin system identification}

Analysis of the amino-acid spin systems began with the amide to aliphatic region of TOCSY spectra of Waglerin-1 in $\mathrm{H}_{2} \mathrm{O}$ (Fig. 2). The $\mathrm{C}_{\alpha}$ proton resonances were identified by comparison with the fingerprint region of DQF-COSY spectra $\left(\mathrm{H}_{2} \mathrm{O}\right)$ (Fig. 3). Four groups of spin systems were initially identified from the TOCSY experiment by inspection of the $\mathrm{NH}$ to $\mathrm{C}_{\alpha} \mathrm{H}, \mathrm{C}_{\beta} \mathrm{H}, \mathrm{C}_{\gamma} \mathrm{H}$ and $\mathrm{C}_{\delta} \mathrm{H}$ connections. The four groups were (1) Gly with two $\mathrm{C}_{\mathrm{a}}$ proton resonances, (2) Ile and Leu spin systems, (3) AMX spin systems with $C_{\alpha}$ proton resonance between 2.5 and 4.0 ppm, and (4) long side-chain spin systems (Lys, Arg and Glu) where at least three cross-peaks from the side chain to the amide proton were observed.

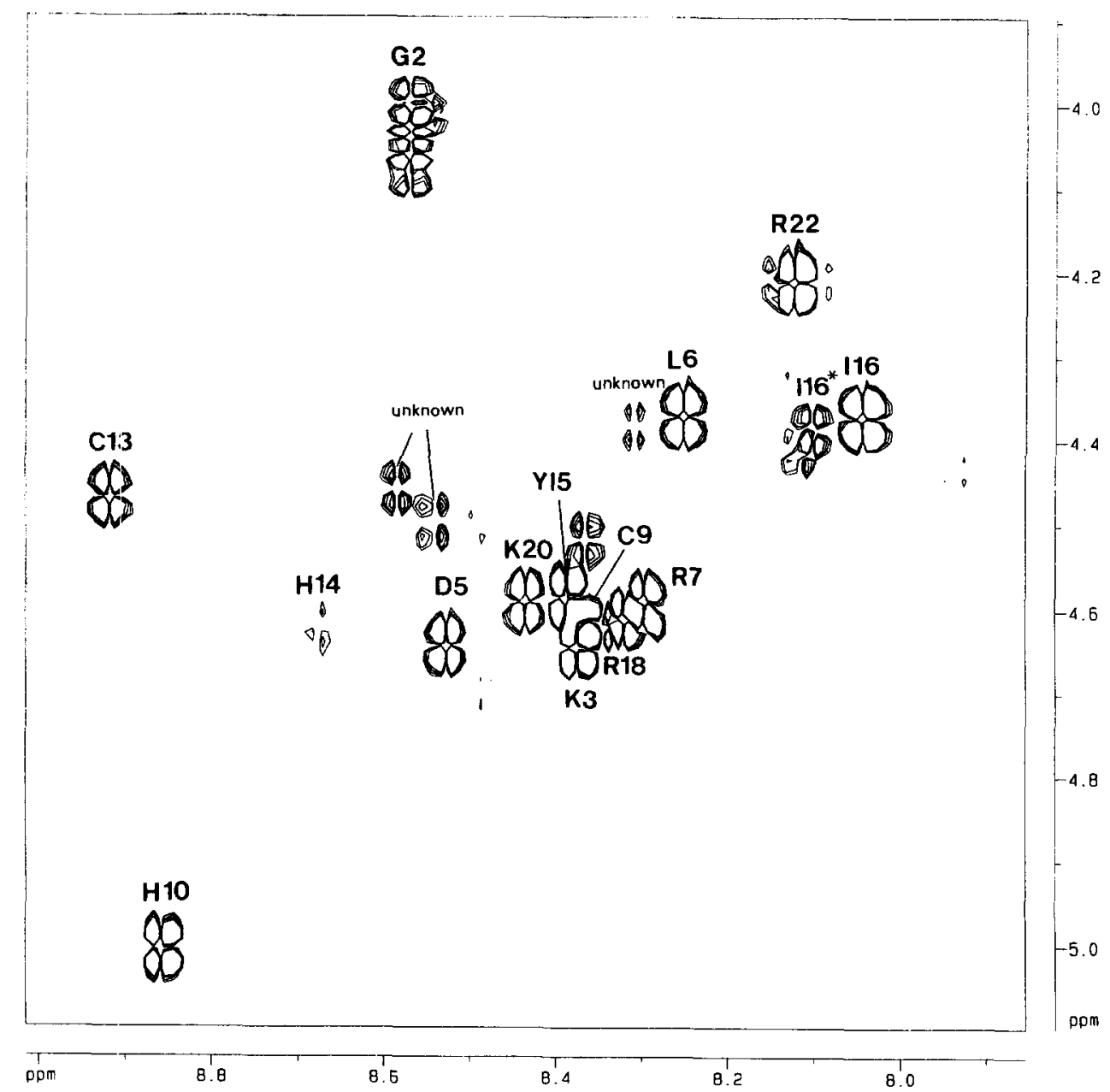

Fig. 3. The fingerprint region of the DQF-COSY spectrum of waglerin I dissolved in $90 \% \mathrm{H}_{2} \mathrm{O} / 10 \%{ }^{2} \mathrm{H}_{2} \mathrm{O}$ at pH 3.0. 


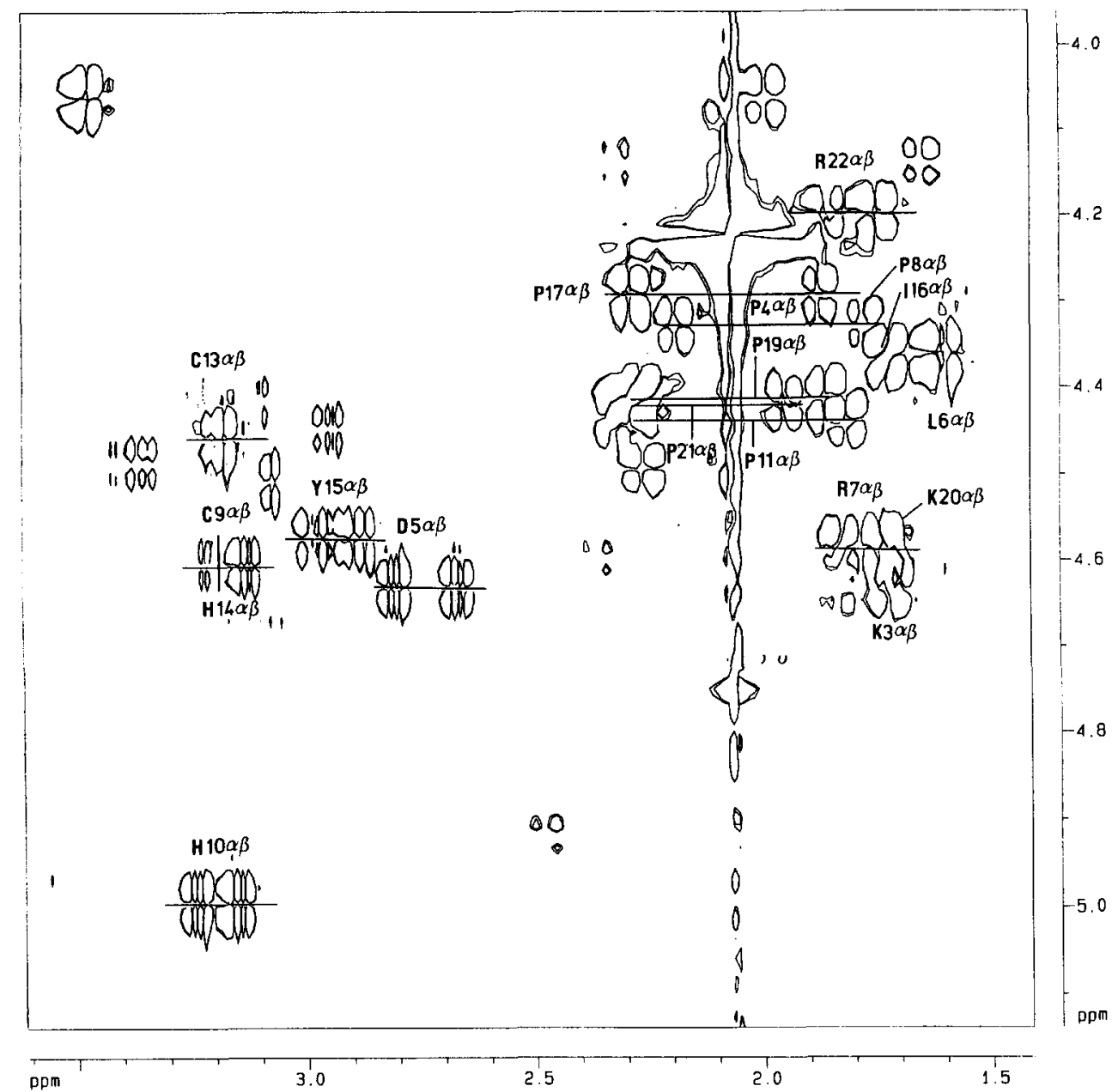

Fig. 4. An expansion of a DQF-COSY spectrum of waglerin I dissolved in $\mathrm{H}_{2} \mathrm{O}$ at $\mathrm{pH} 3.0$ shows 6 AMX and other than AMX spin systems.

Table 1

${ }^{\prime} \mathrm{H}-\mathrm{NMR}$ chemical shifts of waglerin- $1\left(\mathrm{H}_{2} \mathrm{O}\right.$ containing $\left.10 \% \mathrm{D}_{2} \mathrm{O}, 27^{\circ} \mathrm{C}\right)$

\begin{tabular}{|c|c|c|c|c|c|c|}
\hline \multirow[t]{2}{*}{ Residue } & \multicolumn{6}{|c|}{ Chemical shift (ppm) } \\
\hline & $\overline{\mathrm{NH}}$ & $\mathrm{C}_{\alpha} \mathrm{H}$ & $\mathrm{C}_{\beta} \mathrm{H}$ & $\mathrm{C}_{\gamma} \mathrm{H}$ & $\mathrm{C}_{\delta} \mathrm{H}$ & others \\
\hline Gly-1 & & $3.44,4.10$ & & & & \\
\hline Gly-2 & 8.50 & $3.98,4.03$ & & & & \\
\hline Lys-3 & 8.30 & 4.62 & 1.70 & $1.50,1.81$ & 1.69 & $3.02\left(\mathrm{C}_{\varepsilon} \mathrm{H}\right), 7.51\left(\mathrm{~N}_{\varepsilon} \mathrm{H}_{3}\right)$ \\
\hline Pro-4 & & 4.37 & 2.26 & $1.93,1.98$ & $3.64,3.82$ & \\
\hline Asp-5 & 8.46 & 4.60 & $2.65,2.78$ & & & \\
\hline Leu-6 & 8.18 & 4.33 & 1.59 & 1.59 & $0.81,0.89$ & \\
\hline Arg-7 & 8.22 & 4.56 & $1.71,1.80$ & 1.63 & 3.20 & $7.29\left(\mathrm{~N}_{\varepsilon} \mathrm{H}\right)$ \\
\hline Pro-8 & & 4.30 & $1.73,2.18$ & 1.96 & $3.58,3.72$ & \\
\hline Cys-9 & 8.28 & 4.57 & $3.11,3.21$ & & & \\
\hline His-10 & 8.78 & 4.97 & $3.14,3.22$ & & & $7.35\left(\mathrm{C}_{2} \mathrm{H}\right), 8.61\left(\mathrm{C}_{4} \mathrm{H}\right)$ \\
\hline Pro-11 & & 4.46 & $1.80,2.31$ & $1.98,2.07$ & $3.45,4.03$ & \\
\hline Pro-12 & & 4.38 & 2.24 & $1.88,1.93$ & $3.50,3.61$ & \\
\hline Cys-13 & 8.84 & 4.43 & 3.16 & & & \\
\hline His- 14 & 8.59 & 4.57 & $3.11,3.23$ & & & $7.24\left(\mathrm{C}_{2} \mathrm{H}\right), 8.55\left(\mathrm{C}_{4} \mathrm{H}\right)$ \\
\hline Tyr-15 & 8.32 & 4.56 & $2.89,2.98$ & & & $6.78\left(\mathrm{C}_{2}{ }_{6} \mathrm{H}\right), 7.05\left(\mathrm{C}_{3,5} \mathrm{H}\right)$ \\
\hline Ile-16 & 7.97 & 4.34 & 1.71 & $1.03,1.40$ & $0.79,0.83\left(\mathrm{C}_{\gamma} \mathrm{H}_{3}\right)$ & \\
\hline Pro-17 & & 4.26 & $1.86,2.25$ & 1.98 & $3.61,3.63$ & \\
\hline Arg-18 & 8.24 & 4.57 & 1.81 & 1.73 & 3.21 & $7.16\left(\mathrm{~N}_{\varepsilon} \mathrm{H}\right)$ \\
\hline Pro-19 & & 4.39 & $1.85,2.25$ & 1.98 & $3.57,3.78$ & \\
\hline Lys-20 & 8.36 & 4.55 & 1.71 & $1.50,1.81$ & 1.69 & $3.00\left(\mathrm{C}_{\varepsilon} \mathrm{H}\right), 7.51\left(\mathrm{~N}_{\varepsilon} \mathrm{H}_{3}\right)$ \\
\hline Pro-21 & & 4.39 & $1.93,2.26$ & 1.98 & $3.64,3.82$ & \\
\hline Arg-22 & 8.05 & 4.17 & $1.73,1.85$ & 1.63 & 3.20 & $7.16\left(\mathrm{~N}_{\varepsilon} \mathrm{H}\right)$ \\
\hline
\end{tabular}



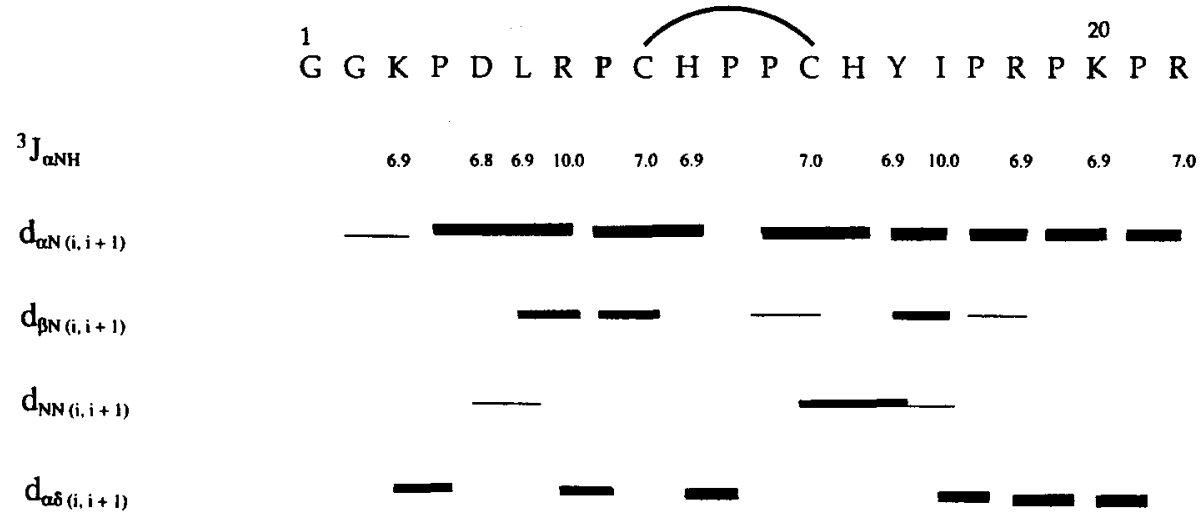

Fig. 5. Summary of the observed, sequential NOEs, coupling constants used in assignments. The relative intensities of NOE, classified into strong, medium and weak, are indicated by the thickness of the lines. The value (in $\mathrm{Hz})$ of coupling constants $\left({ }^{3} J_{\alpha \mathrm{NH}}\right)$ are also shown.

The Gly ${ }^{2}$ residues with different $\mathrm{C}_{\alpha} \mathrm{H}$ resonances was identified by observing pairs of $\mathrm{C}_{\alpha} \mathrm{H}$ to $\mathrm{NH}$ cross-peaks in the fingerprint region of the DQF-COSY spectra of waglerin $\mathrm{I}$ in $\mathrm{H}_{2} \mathrm{O}$ (Fig. 3) and by the characteristically large $J$ couplings between the $\mathrm{C}_{\alpha} \mathrm{H}$ proton pairs. The Gly ${ }^{1}$ resonances were assigned by the sequential connectivities and the two $\mathrm{C}_{\alpha} \mathrm{H}$ connectivity in the DQF-COSY spectrum. Two methyl-containing residues (Ile and Leu) were unambiguously assigned.

The $\mathrm{C}_{\alpha} \mathrm{H}$ to $\mathrm{C}_{\beta} \mathrm{H}$ cross-peaks of the long side-chain residues are shown in an expansion of the DQF-COSY spectra in $\mathrm{H}_{2} \mathrm{O}$ (Fig. 4). Waglerin I contains seven Pro,

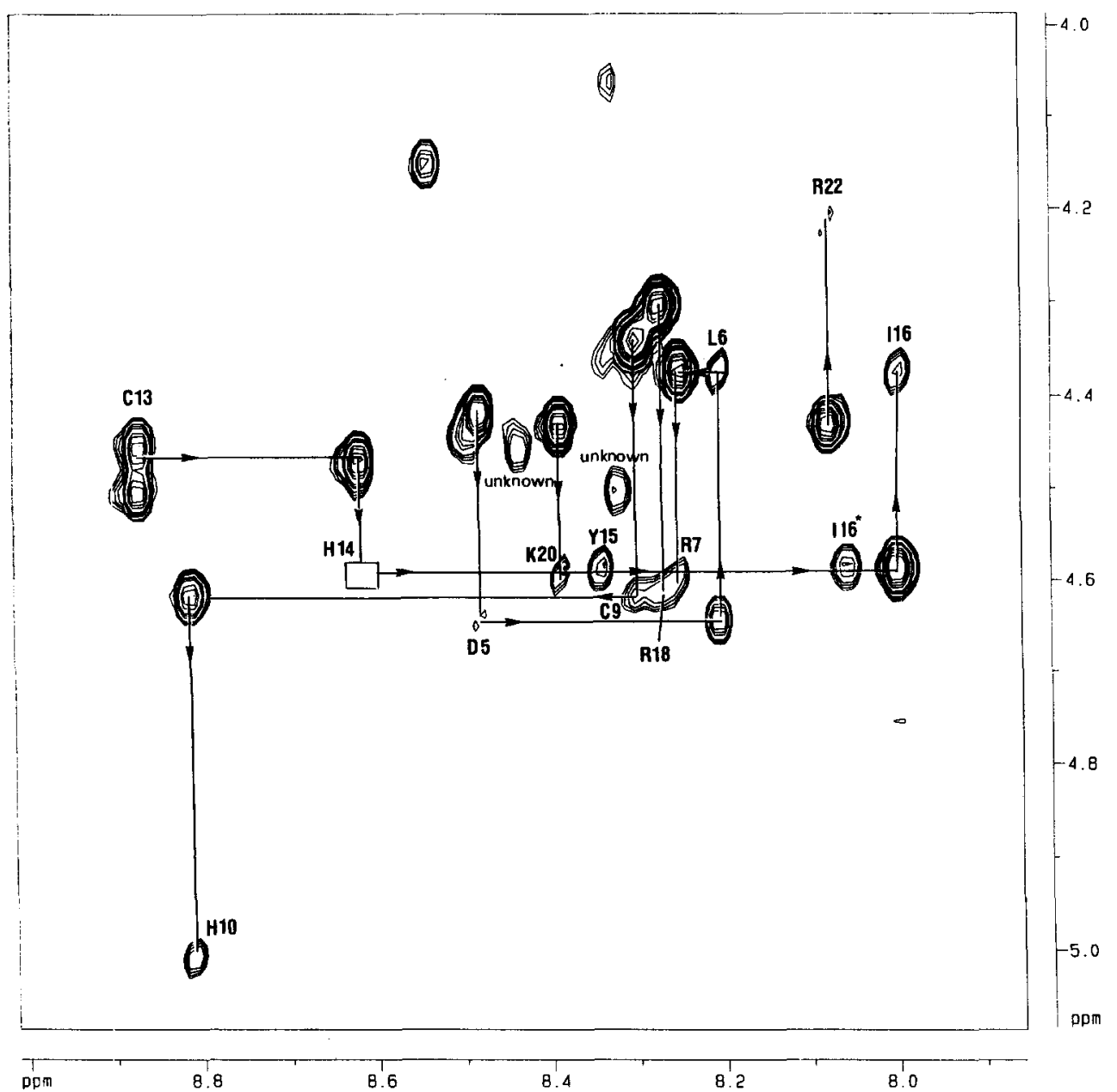

Fig. 6. NOESY spectrum of waglerin I recorded in $90 \% \mathrm{H}_{2} \mathrm{O} / 10 \%{ }^{2} \mathrm{H}_{2} \mathrm{O}$ at $\mathrm{pH} 3.0$ for a mixing period of $300 \mathrm{~ms}$. The sequential $\mathrm{d}_{\alpha \mathrm{N}}$ connectivities are indicated for the sequence of residues 1-22. 
three Arg and two Lys residues. Of these spin systems, seven Pro were identified by observing the complete connectivity pattern between the protons. Arg and Lys resonances were distinguished from each other and were assigned from sequential connectivities.

An expansion of a DQF-COSY spectrum in Fig. 4 shows $\mathrm{C}_{\alpha} \mathrm{H}$ to $\mathrm{C}_{\beta} \mathrm{H}$ cross-peaks of $6 \mathrm{AMX}$ spin systems. Waglerin I contains one Tyr, two His, two Cys and one Asp residue. The aromatic ring protons of Tyr and His were readily determined by inspection of the spectra. The AMX spin systems of these aromatic residues were assigned on the basis of NOEs between the aromatic protons and the respective $C_{\beta}$ protons of the residues $[26,27]$.

\subsection{Sequential assignments}

Using the sequential assignment procedure, specific assignments for the amino acids were obtained, as shown in Table 1. The sequential NOE connectivities $d_{N N}, d_{\alpha N}$ and $d_{\beta N}$, together with other NMR parameters are summarized in Fig. 5. The regions of the NOESY spectra containing the $\mathrm{d}_{\alpha \mathrm{N}}(i, i+1)$ sequential NOE connectivities is shown in Fig. 6. The sequential connectivities $\mathrm{C}_{\alpha} \mathrm{H}_{i-1}, \mathrm{C}_{\delta} \mathrm{H}_{i}$ and $\mathrm{C}_{\alpha} \mathrm{H}_{i-1}, \mathrm{C}_{\alpha} \mathrm{H}_{i}$ for the proline are shown in Fig. 7. Because of the presence of $\mathrm{C}_{\alpha} \mathrm{H}_{11} / \mathrm{C}_{\alpha} \mathrm{H}_{12}$ cross-peak, $\mathrm{Pro}^{12}$ is assumed to be in the cis conformation. The presence of $\mathrm{C}_{\alpha} \mathrm{H}_{i-1}, \mathrm{C}_{\delta} \mathrm{H}_{i}$ NOE peaks and the absence of $\mathrm{C}_{\alpha} \mathrm{H}_{i-1} / \mathrm{C}_{\alpha} \mathrm{H}_{i}$ cross-peaks and any exchange peaks for the other six prolines indicated that these prolines are in the trans conformation [28].

\subsection{Selection and analysis of calculated structures}

As shown in Fig. 8, the total potential-energy of the protein is relatively constant in the last 12 ps calculation. However, several local minima are discernible. Of these, we selected 19 local minima based on lower energy values and small amount of NOE violations which were superimposed and shown in Fig. 9. The good agreement between all selected structures indicates the good convergence of all the structures. The average RMS deviation from the mean structure is $0.90 \AA$ for the backbone atoms and 1.69 $\AA$ for all atoms. Excluding the $\mathrm{C}$ - and $\mathrm{N}$-termini regions (residue 1-6 and 17-22), the RMS deviation from the

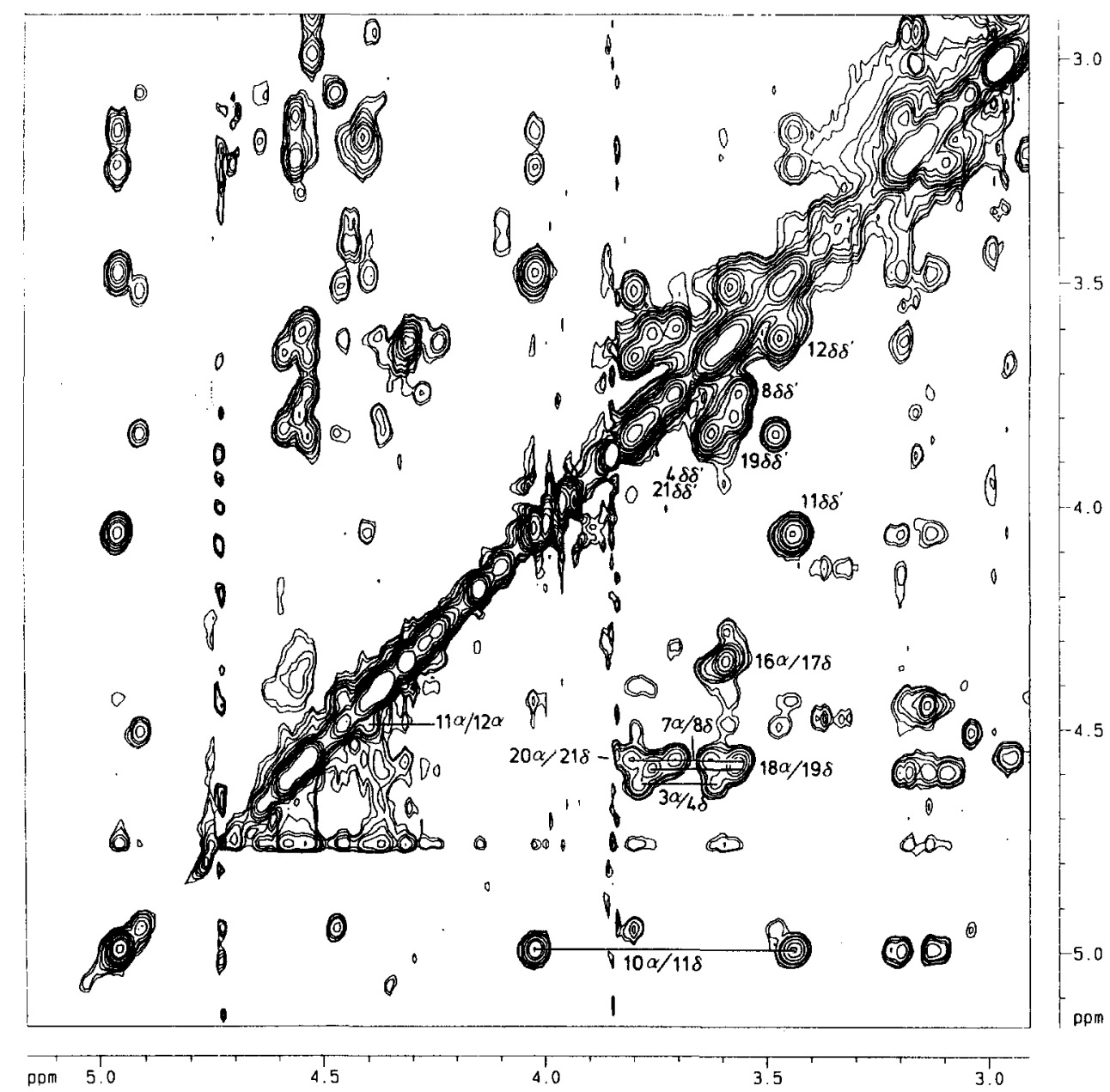

Fig. 7. NOESY spectrum of waglerin I recorded in $90 \% \mathrm{H}_{2} \mathrm{O} / 10 \%{ }^{2} \mathrm{H}_{2} \mathrm{O}$ at pH 3.0 for a mixing period of $300 \mathrm{~ms}$. The cross-peaks $\left(\mathrm{C}_{\alpha} \mathrm{H}_{i-1} \mathrm{C}_{\delta} \mathrm{H}_{i}\right)$ and $\mathrm{C}_{\alpha} \mathrm{H}_{i-1}, \mathrm{C}_{\alpha} \mathrm{H}_{i}$ ) of Xaa-Pro are indicated. 


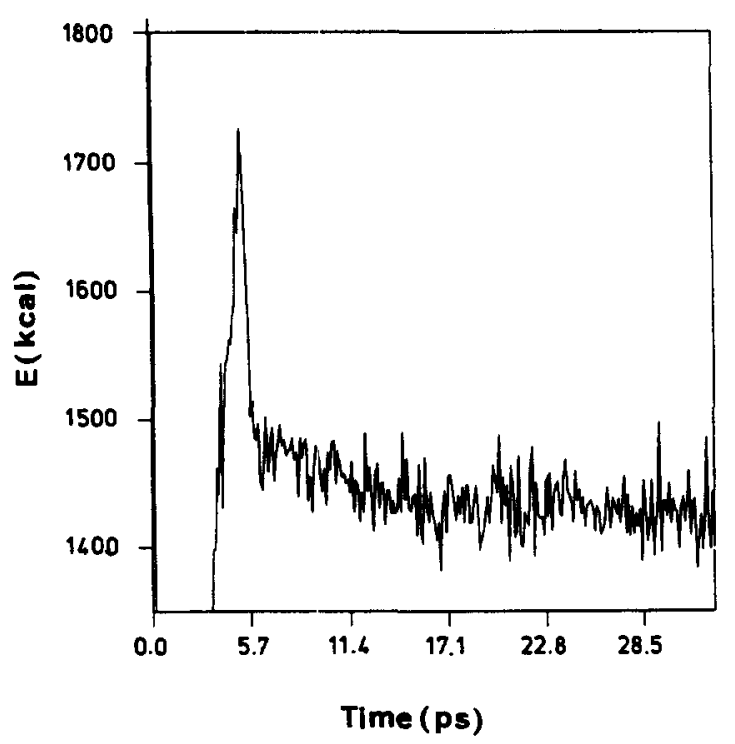

Fig. 8. The plot showing the variation of the total energy with respect to the SA time steps in ps.

mean structure is $0.41 \AA$ for the backbone atoms. Although the CD (Fig. 10) and NMR studies, including NOEs, coupling constant and proton exchange rates suggest the absence of particular secondary structure, the tertiary folding is rather defined, except for $\mathrm{C}$ - and $\mathrm{N}$-termini regions which are less defined. These are confirmed by the highest peak noted in the RMSD plot for the mean structure and the number of NOE constraints (Fig. 11). More NOE constraints correlates with better defined residues.

Although there are relatively few inter-residue NOE constraints, the tertiary structure of waglerin $I$ is well-defined. The major contribution is probably due to the presence of the seven proline residues. All of which, except Pro-12, exist in the trans conformation as clearly indicated by the presence of $\mathrm{C}_{\alpha} \mathrm{H}_{i-1}, \mathrm{C}_{\delta} \mathrm{H}_{i}$. This is unusual, since proline preferrably appears in the trans conformation due to the presence of steric interaction between the pyrroli-

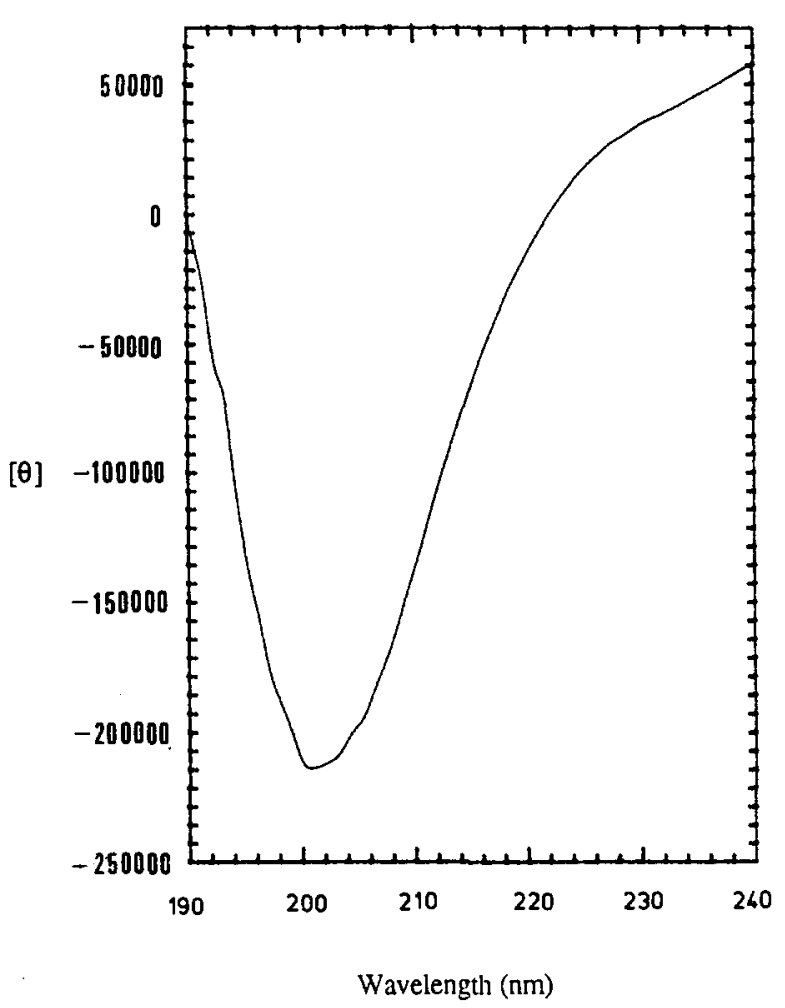

Fig. 10. Circular dichroism spectra of waglerin I.

dine ring $\Delta$-position and the preceding residue in a cis Xaa-Pro sequence (Hinck et al. [28]). The presence of a defined tertiary structure is further substantiated by the observation of relatively large ${ }^{3} J_{\mathrm{C} \alpha \mathrm{H}-\mathrm{NH}}(10 \mathrm{~Hz})$ for $\mathrm{R} 7$ and I16, suggesting the presence of well-defined dihedral angles at R7 and I16. We should also point out that there are five unassigned extra peaks in the finger print region. The HPLC experiments clearlly shows that this peptide is highly pure. In addition, the NMR experiments at different temperature also indicate these unknow peaks are due to the formation of minor conformer. From intensity mea-
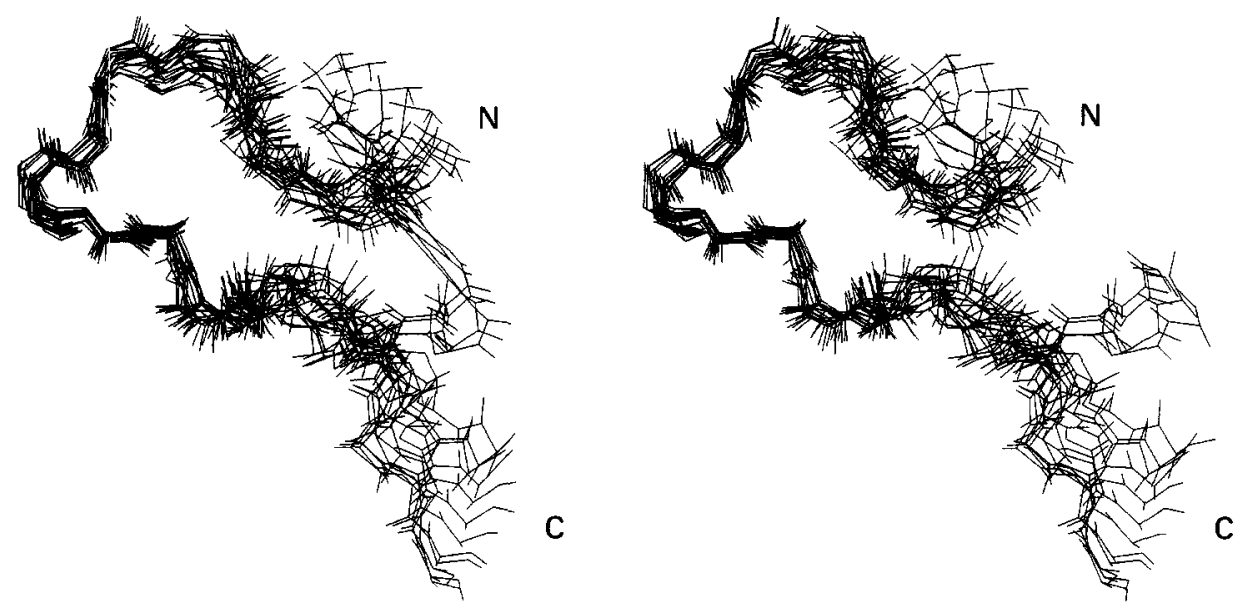

Fig. 9. Stereo views of the structure of waglerin I calculated by simulated annealing. The backbone atoms of the 19 selected solution structures are superimposed. 

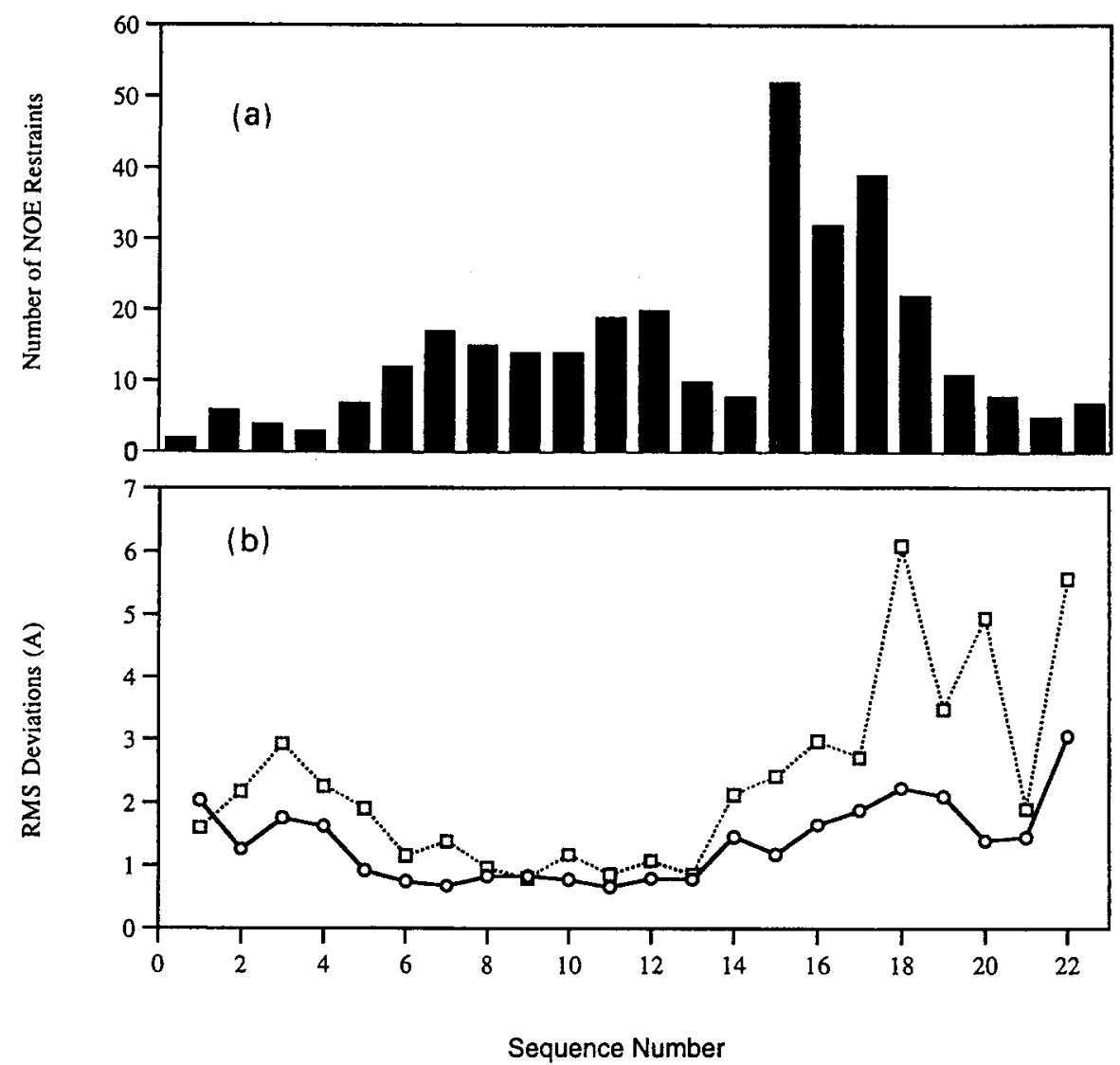

Fig. 11. (a) Schematic diagram showing the distribution of the NOE restraints used in the structure calculation. (b) Variation of RMSD values of the 19 solution structures of waglerin I relative to their mean structure. Backbone (- $O_{-}$) and side-chain (- $\square-$ ) RMSD values are shown, respectively.

surements, we estimate that the population of the minor conformer is less than $15 \%$. Even though the weak intensities of these peaks preclude us from making definitive assignment, a close inspection reveals that these extra peaks belong to the AMX spin systems (Fig. 2). Waglerin I consists of six amino acids with AMX spin system (D5, $\mathrm{C} 9, \mathrm{H} 10, \mathrm{C} 13, \mathrm{H} 14$ and Y15). Since all of the unassigned peaks are AMX spin systems, it is likely that they are adjacent residues. The likely candidate of these unassigned AMX peaks are $\mathrm{C} 9, \mathrm{H} 10, \mathrm{C} 13, \mathrm{H} 14$ and $\mathrm{Y} 15$ in the central loop region. Thus, the central loop region may exist in two conformational states. The lack of exchange cross peaks between the two conformers suggest that the conformational change is slow in the NMR time scale. Presence of a second conformer can occur if Pro- 11 and Pro- 12 exist different stereoisomers.

\subsection{Relationship of structure and function}

Waglerin I acts on both pre- and post-synaptic sites of the mouse motor endplate. The ability of the peptide to bind to presumably structurally different sites is probably due to the flexibility of the peptide to assume various conformational states. This observation also agrees with the NMR studies. The main features of the conformation of the peptide is a central loop formed by a disulfide bond with highly basic $\mathrm{N}$ - and $\mathrm{C}$-termini. The central loop (9-13 residues) is fixed by one disulfide bond and the cis-peptide bond of Pro ${ }^{11}$-Pro ${ }^{12}$ with high convergence is the crucial part for biological function [7]. The absence of defined secondary structure in the $\mathrm{N}$ - and C-termini suggests that the two ends are likely to be more disorder. It is interesting to note that our determined structure does not agree with the computer model, in which a helical segment in the C-terminus and a slightly vibrating ' $k$ not' in the $\mathrm{N}$-terminus was proposed [29].

Many polypeptide toxins have been successfully used to investigate receptors and ion channels, for example, black widow spider toxin [30], funnel-web spider toxin [31], the scorpion toxin charybdotoxin [32] and the snake toxin $\alpha$-bungatoxin [33]. The dual action of this peptide makes it unusual among natural peptide toxins, and further investigation of the peptide and its analogs could yield new information about neurotransmitter release.

\section{Acknowledgements}

We thank Dr. C.Y. Lee in Department of Pharmacology, College of Medicine, National Taiwan University for 
his comments and suggestions, and the National Science Council, Taipei, Taiwan for research grants to S.H. Wu, T.H. Huang and K.T. Wang.

\section{References}

[1] Leviton, A.E. (1964) Philips J. Sci. 93, 251-276.

[2] Smith, M.A. and Hindle, E. (1931) Trans. R. Soc. Trop. Med. Hyg. $25,115-120$.

[3] Minton, S.A. (1968) Toxicon 6, 93-97.

[4] Tan, N.-H. and Tan, C.-S. (1989) Toxicon. 27, 349-357.

[5] Teng, C.M., Huang, M.L., Huang, T.F, and Ouyang, C. (1989) Biochim. Biophys. Acta 992, 258-264.

[6] Weinstein, S.A., Schmidt, J.J., Bermheimer, A.W. and Smith, L.A. (1991) Toxicon 29, 227-236.

[7] Schmidt, J.J., Weinstein, S.A. and Smith L.A. (1992) Toxicon 30, 1027-1036.

[8] Hsieh, W.H., Tsai, M.C., Lse, C.Y. and Smith, L.A. (1994) Toxicon $32,532-533$.

[9] Lee, C.Y., Lin, W.W. and Smith, L.A. (1994) Toxicon 32, 526.

[10] Aiken, S.P., McArdle, J.J., Sellin, L.C., Schmidt, J.J. and Weinstein, S.A. (1991) Pharmacologist 33, 186.

[11] Aiken, S.P., Sellin, L.C., Sihmidt, J.J., Weinstein, S.A. and McArdle, J.J. (1992) Pharmacol. Toxicol. 70, 459-462.

[12] Rance, M., Sørensen, O.W., Bodenhausen, G., Wagner, G., Ernst, R.R. and Wüthrich, K. (1983) Biochem. Biophys. Res. Commun. 117, 479-485.

[13] Jeener, J., Meier, B.M., Bachmann, P. and Ernst, R.R. (1979) J. Chem. Phys. 71, 4546-4553.

[14] Macura, S., Huang, Y., Surer, D. and Ernst, R.R. (1981) J. Magn. Reson. 43, 259-281.
[15] Braunschweiler, L. and Ernst, R.R. (1983) J. Magn. Reson. 53, 521-528.

[16] Bax, A. and Davies D.G. (1985) J. Magn. Reson. 65, 355-360.

[17] Redfield, A.G. and Kunz, S.D. (1975) J. Magn. Reson. 19, 250-254.

[18] Marion, D. and Wüthrich, K. (1983) Biochem. Biophys. Res. Commun. 113, 967-974.

[19] Wuithrich, K., Billeter, M. and Braun, W. (1983) J. Mol. Biol. 169, 949-961.

[20] Karplus, M. (1963) J. Am. Chem. Soc. 85, 2870-2871.

[21] Pardi, A., Billeter, M. and Wuithrich, K. (1984) J. Mol. Biol. 180, 741-751.

[22] Gómez-Sánchez, A., Borrachero Moya, P. and Bellanato, J. (1984) Carbohydr. Res. 135, 101-116.

[23] Bye, E., Mosted, A. and Romming, C. (1973) Acta. Chem. Scand. 27, 471-484.

[24] Gelin, B.R. and Karplus, M. (1975) Proc. Natl. Acad. Sci. USA 72, 2002-2006.

[25] Wüthrich, K. (1986) NMR of Protein and Nucleic Acid, Wiley, New York.

[26] Wagner, G. and Wüthrich, K. (1982) J. Mol. Biol. 155, 347-366.

[27] Wider, G., Lee, K.H. and Wüthrich, K. (1982) J. Mol. Biol. 155, 367-388.

[28] Hinck, A.P., Eberhardt, E.S. and Markley, J.L. (1993) Biochemistry 32, 7377-7387.

[29] Hyvönen, M., Mattila, K., Rantala, T.T. and Sellin, L.C. (1994) Biophysical J. 66, A63.

[30] Longenecker, H.E., Hurlbut, W.P.J., Mauro, A. and Clark, A.W. (1970) Nature. 225, 701-703.

[31] Llinás, R., Sugimori, M., Lin, J.-W. and Cherksey, B. (1989) Proc. Natl. Acad. Sci. USA 86, 1689-1693.

[32] Deutsch, C., Price, M., Lee, S., King, V.F. and Garcia, M.L. (1991) J. Biol. Chem. 266, 3668-3674.

[33] Chang, C.C. and Lee, C.Y. (1963) Arch. Int. Pharmacodyn. Ther. 144, 241-257. 